(c) American Dairy Science Association, 2003.

\title{
Genetic Change for Clinical Mastitis in Norwegian Cattle: a Threshold Model Analysis
}

\author{
B. Heringstad, ${ }^{\star}$ R. Rekaya,† D. Gianola, ${ }^{\star} \ddagger$ G. Klemetsdal, ${ }^{\star}$ and K. A. Weigel‡ \\ *Department of Animal Science, Agricultural University of Norway, \\ P.O. Box 5025, N-1432 Ås, Norway \\ †Department of Animal and Dairy Science, University of Georgia, \\ Athens, GA 30602 \\ ‡Department of Dairy Science, University of Wisconsin \\ Madison 53706
}

\section{ABSTRACT}

Records of clinical mastitis on 1.6 million first-lactation daughters of 2411 Norwegian Cattle sires that were progeny tested from 1978 through 1998 were analyzed with a threshold model. The main objective was to infer genetic change for the disease in the population. A Bayesian approach via Gibbs sampling was used. The model for the underlying liability had age at first calving, month $\times$ year of calving, herd $\times 3$-year-period, and sire of the cow as explanatory variables. Posterior mean (SD) of heritability of liability to clinical mastitis was 0.066 (0.003). Genetic evaluations (posterior means) of sires both in the liability and observable scales were computed. Annual genetic change of liability to clinical mastitis for progeny tested bulls born from 1973 to 1993 was assessed. The linear regression of mean sire effect on year of birth had a posterior mean (SD) of -0.00018 (0.0004), suggesting a nearly constant genetic level for clinical mastitis. However, an analysis of sire posterior means by birth-year of daughters indicated an approximately constant genetic level in the cow population from 1976 to $1990(-0.02 \% / y r)$, and a genetic improvement thereafter $(-0.27 \% / y r)$. This reflects more emphasis on mastitis in selection of bulls in recent years. Corresponding results obtained with a standard linear model analysis were $-0.01 \%$ and $-0.23 \%$ per year, respectively (regression of sire predicted transmitting ability on birth-year of daughters). Genetic change seems to be slightly understated with the linear model, assuming the threshold model holds true.

(Key words: Bayesian methods, clinical mastitis, genetic change, heritability, threshold model)

Abbreviation key: $\mathbf{C M}=$ clinical mastitis, $\mathbf{N R F}=$ Norwegian Cattle, PTA = predicted transmitting ability .

Received March 19, 2002.

Accepted July 12, 2002

Corresponding author: B. Heringstad; e-mail: bjorg.heringstad@ ihf.nlh.no.

\section{INTRODUCTION}

Due to a seemingly unfavorable genetic correlation between mastitis and milk yield (Heringstad et al., 1999), single-trait selection for increased milk production is expected to result in a genetic deterioration of resistance to the disease. Interest in genetic improvement of functional and health traits, including mastitis, has increased in recent years, and assessment of the effects of selection for a broad breeding objective over time is, therefore, important.

In Norwegian Cattle (NRF), clinical mastitis (CM) has been included in the breeding objective since 1978 . $\mathrm{NRF}$ is the population that has been recorded and selected against the disease for the longest time period (Heringstad et al., 2000). Thus, it represents one of the few dairy populations where assessment of the effectiveness of long-term selection against mastitis is possible. In analyses of CM data in NRF from 1978 to 1995, Heringstad et al. (2001a) found a flat trend for estimated breeding values for CM for bulls born from 1974 to 1990. However, an increasing selection differential for $\mathrm{CM}$ in the desired direction was noted for bull sires born from 1983 onwards. Arguably, this is due to an increase in the weight placed on CM, relative to milk production, in the breeding objective over recent years. These authors expected this to influence genetic level for CM of sons born from 1990 onwards favorably, and pointed out that genetic progress for CM should take place with NRF's current breeding objective (Heringstad et al., 2001a).

Heringstad et al. (2001a) used a linear sire model to estimate genetic change for $\mathrm{CM}$ in $\mathrm{NRF}$, although a threshold model is theoretically more appealing for analysis of binary response data (Gianola, 1982). Several studies have suggested that threshold and linear models produce similar sire rankings with respect to single-trait genetic evaluation (Meijering, 1985; Weller et al., 1988), especially when progeny group sizes are large. However, in analysis of trends where data from long time periods must be used, changes in prevalence 
Table 1. Summary statistics of the dataset used for analysis of genetic change of clinical mastitis in first-lactation Norwegian Cattle.

\begin{tabular}{lc}
\hline Records, no. & $1,599,864$ \\
Sires, no. & 2,411 \\
Daughters per sire, mean no. & 664 \\
Herds, no. & 28,491 \\
Herd $\times$ year classes, no. & 384,522 \\
Records per herd $\times$ year class, mean no. & 4.2 \\
Herd $\times$ period $^{1}$ classes, no. & 134,752 \\
Records per herd $\times$ period $^{1}$ class, mean no. & 11.9 \\
Mastitis frequency $^{2} \%$ & 15.8 \\
\hline
\end{tabular}

${ }^{1}$ Herd $\times$ period was defined from 28,491 herds and 6 periods where year of calving $<1984$ was the first period, year of calving $>1995$ was the last period, and the others were 3-yr periods.

${ }^{2}$ Mastitis frequency $=$ percentage of cows with at least one record of veterinary treatment of clinical mastitis in the period from $15 \mathrm{~d}$ prepartum to $120 \mathrm{~d}$ after first calving.

of binary traits over time may favor a threshold model over a standard linear model analysis.

The objectives of this paper were: 1) to infer heritability and genetic change for CM in NRF with a threshold model, using all the Norwegian mastitis data from 1978 to 1999,2 ) to compute the posterior distribution of annual genetic change, which provides a measure of uncertainty of inferences about genetic change, and 3) to compare sire evaluations and estimates of genetic change from a threshold model, obtained with a Bayesian MCMC implementation, with those found with linear sire model and REML-BLUP methodology.

\section{MATERIALS AND METHODS}

\section{Data}

Records were extracted from a research database containing phenotypic information from the Norwegian Dairy Herd Recording from 1978 onwards. A total of 1.6 million first-lactation daughters of $2411 \mathrm{NRF}$ sires, progeny tested from 1978 through 1998, were included. Records of daughters of AI sires with second-batch daughters only (i.e., bulls progeny tested earlier than 1978 and foreign-proven bulls) and records of bulls with less than 20 daughters were excluded. A record was included if first calving was between September 1, 1978, and September 1, 1998, and if age at first calving was between 450 and $1200 \mathrm{~d}$, provided the lactation started with a normal calving. To ensure that herds were participating in the health recording system, only records from herds with at least one health event recorded during the year the cow calved were accepted.

Mastitis was defined as a binary trait $(0=$ no mastitis, $1=$ mastitis), based on whether or not the cow had at least one veterinary treatment of CM in the period going from $15 \mathrm{~d}$ prepartum to $120 \mathrm{~d}$ after first calving. This is the period currently used for genetic evaluation of mastitis in Norway. The structure of the dataset is shown in Table 1. Overall mastitis frequency was $15.8 \%$
(Table 1), increasing from 1978 to 1995 , and decreasing thereafter, as shown in Figure 1. As the number of cows per herd is small in Norway, modeling contemporary groups as herd $\times$ year classes can induce an "extreme category" problem (i.e., classes with all responses equal to "0" or " 1 "). Grouping together records within herds over longer periods of time can alleviate the problem. In this study, records were grouped according to herd $\times$ period classes, as shown in Table 1 . With this grouping, the mean number of records per herd-effect class increased from about 4 to 12 . The sire pedigree file had 2530 males including the 2411 sires with daughters in the dataset. Additive genetic relationships between males were calculated from this file.

\section{Threshold Model}

A threshold-liability model (Wright, 1934; Gianola, 1982; Gianola and Foulley, 1983) was used for analysis of the binary CM data. The threshold model postulates an underlying continuous random variable, liability $(\lambda)$, such that an observed binary response takes the value 1 if $\lambda$ is larger than a fixed threshold $(\tau)$, and 0 otherwise. Given the mean and variance, liability was assumed to be normally distributed. Since with binary data the threshold and the residual variance $\left(\sigma^{2}{ }_{\mathrm{e}}\right)$ are not identifiable, these parameters were set to arbitrary values $(\tau$ $=0$ and $\sigma^{2}=1$ ).

A linear sire model was used for analysis of the underlying liability to CM. In matrix notation the model can be written as:

$$
\lambda=\mathbf{X} \boldsymbol{\beta}+\mathbf{Z}_{\mathbf{h}} \mathbf{h}+\mathbf{Z}_{\mathbf{s}} \mathbf{s}+\mathbf{e}
$$

where $\lambda$ is a vector of unobserved liabilities of all cows and $\beta$ is a $256 \times 1$ vector of age of calving and month $\times$ year of calving classes ( 15 age of calving classes, where $<20 \mathrm{mo}$ is the first class, $>32 \mathrm{mo}$ is the last class, and the other classes are in 1-mo steps; the 241 month $\times$ year of calving classes spanned from September 1978 through September 1998). Further, $\mathbf{h}$ is a vector of herd $\times$ period effects of order 134,752 (from 28,491 herds and 6 periods, where year of calving $<1984$ is the first period, year of calving $>1995$ is the last period, and the others are 3 -yr periods); $\mathbf{s}$ is a vector of sire transmitting abilities of order 2530, and $\mathbf{e}$ is the vector of residual effects. $\mathbf{X}, \mathbf{Z}_{\mathbf{h}}$, and $\mathbf{Z}_{\mathbf{s}}$ are the corresponding incidence matrices.

\section{Bayesian Analysis}

A Bayesian approach using Markov-chain Monte Carlo methods in the implementation (Sorensen et al., 1995), as applied by Heringstad et al. (2001b), was used. 


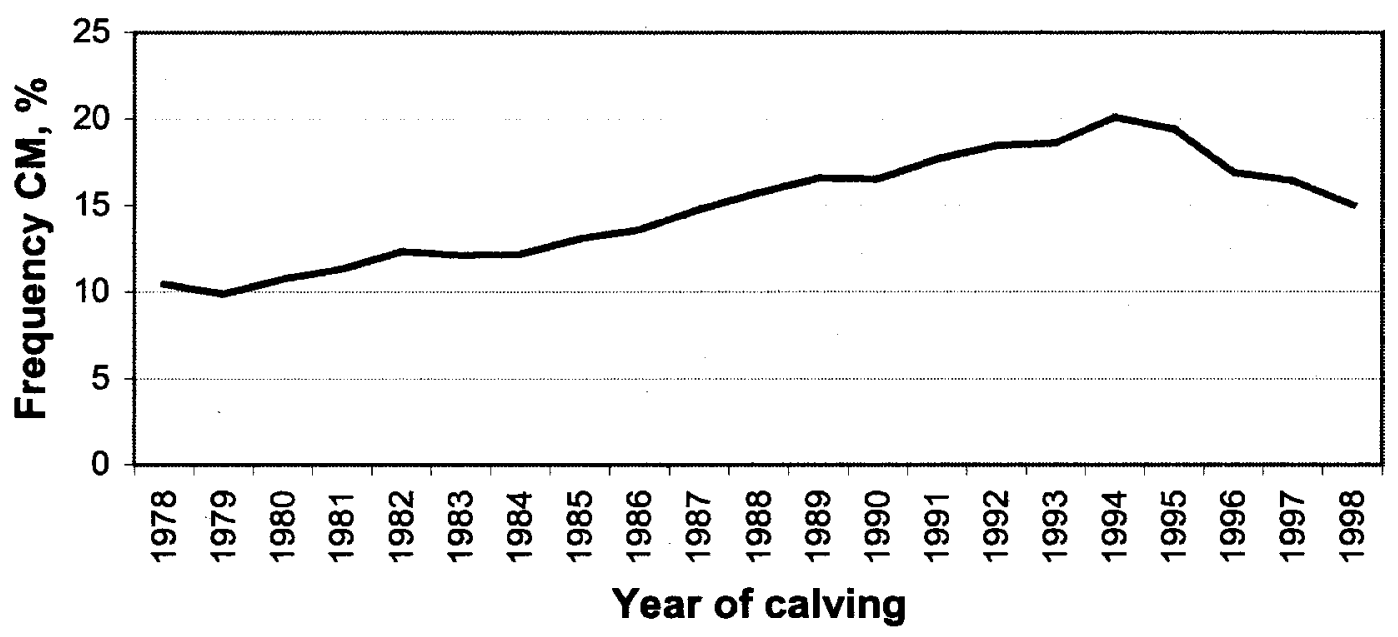

Figure 1. Frequency of clinical mastitis $(\mathrm{CM})$ by year of calving, expressed as percentage of cows with at least one case of clinical mastitis in the period from $15 \mathrm{~d}$ prior to calving to $120 \mathrm{~d}$ after first calving.

Prior distributions. A normal prior distribution with zero mean and variance $\sigma_{\beta}^{2}=10^{6}$ was assigned independently to each of the 256 elements of $\beta$. Hence,

$$
p(\boldsymbol{\beta}) \sim N\left(\mathbf{0}, \mathbf{I} \sigma_{\beta}^{2}\right) .
$$

Since $\sigma_{\beta}^{2}$ is large relative to the residual variance, this prior distribution conveys vague prior knowledge about each of the elements of $\boldsymbol{\beta}$. Based on results of Rekaya et al. (2000), herd $\times$ period effects were assigned a normal prior with an unknown mean and variance to alleviate potential extreme case problems. The prior distribution was:

$$
p\left(\mathbf{h} \mid \eta, \sigma_{h}^{2}\right) \sim N\left(\mathbf{1} \eta, \mathbf{I} \sigma_{\mathrm{h}}^{2}\right)
$$

where $\mathbf{1}$ is a vector of ones and $\eta$ and $\sigma_{h}^{2}$ are the unknown mean and variance of the prior distribution of the herd $\times$ period effects, having prior densities:

$$
p(\eta) \sim U(-10,10)
$$

and

$$
p\left(\sigma_{h}^{2}\right) \sim U(0,1) .
$$

The assumption was that the herd $\times$ period effects were independently and identically distributed, a priori. A multivariate normal distribution was used as prior for the sire effects:

$$
p\left(\mathbf{s} \mid \mathbf{A}, \sigma_{s}^{2}\right) \sim N\left(\mathbf{0}, \mathbf{A} \sigma_{\mathrm{s}}^{2}\right)
$$

where $\mathbf{A}$ is the additive relationship matrix between males, and $\sigma_{s}^{2}$ is the unknown sire variance, for which the following bounded prior was used:

$$
p\left(\sigma_{s}^{2}\right) \sim U(0,1 / 3) .
$$

Posterior distributions. The joint posterior density of all the unknowns is proportional to the product of the densities in [1] through [6] times the conditional distribution of the observations (the product of $\mathrm{n}=$ 1,599,864 independent product-Bernoulli processes):

$$
\begin{gathered}
p\left(\boldsymbol{\beta}, \mathbf{h}, \mathbf{s}, \eta, \sigma_{h}^{2}, \sigma_{\mathrm{s}}^{2} \mid \mathbf{y}\right) \propto p(\mathbf{y} \mid \boldsymbol{\beta}, \mathbf{h}, \mathbf{s}) p(\boldsymbol{\beta}) \\
p\left(\mathbf{h} \mid \eta, \sigma_{h}^{2}\right) p(\eta) p\left(\sigma_{h}^{2}\right) p\left(\mathbf{s} \mid \mathbf{A}, \sigma_{s}^{2}\right) p\left(\sigma_{s}^{2}\right) .
\end{gathered}
$$

Draws from the conditional posterior distributions of the parameters were obtained using a Gibbs sampler with data augmentation (Sorensen et al., 1995). By augmenting [7] with the liabilities, $\lambda_{\mathrm{i}}(\mathrm{i}=1,2, \ldots, \mathrm{n})$, the conditional posterior distributions of all the parameters follow directly from Albert and Chib (1993) and Sorensen et al. (1995).

Convergence diagnostics. Convergence was assessed following Raftery and Lewis (1992) and using the first 20,000 iterations of the Gibbs chain. Using the diagnostics plus visual inspections of trace plots, it was decided to run a total chain length of 55,000 iterations after a burn-in of 10,000 iterations.

\section{Sire Evaluation and Genetic Change}

Genetic evaluations (posterior means) of sires were computed both in the liability and probability scales. 
Posterior means of sires were transformed from the underlying liability scale to the probability scale using:

$$
p_{l}=\Phi\left(\mu+\overline{s_{l}}\right)
$$

where $p_{l}$ is the probability of $\mathrm{CM}$ of an infinite number of daughters of sire $l, \mu$ is the probit corresponding to the mean liability of $\mathrm{CM}$, and $\overline{s_{l}}$ is the posterior mean in the liability scale for sire $l$. Note that this is a firstorder approximation of the posterior mean of $p_{l}=\Phi(\mu$ $+s_{l}$ ); calculation of the latter requires evaluating the normal integral for each draw from the posterior distribution of the transmitting ability of sire $l$, and then averaging over samples for each sire. A second-order Taylor series approximation gave similar results.

The evolution of sire transmitting abilities in the course of time was used to measure genetic change. Annual genetic change was defined as the slope of the linear regression of unobserved sire effects on sires birth-year. The regression was computed for each round of the Gibbs sampler. This constitutes a draw from the posterior distribution of annual genetic change, as defined above. The distribution was estimated from the 45,000 samples, thus obtaining a full description of uncertainty.

Genetic change was evaluated also by plotting average sire posterior means against birth-year of sire and birth-year of daughters, and the annual change was estimated from the slope of the corresponding linear regression. In the first approach, each progeny-tested bull is given equal weight whereas, in the second, sires are weighted according to their number of daughters. Hence, the second measure reflects sire usage as well as possible genetic change in the NRF population.

\section{Linear Model}

For comparison purposes, the data were analyzed also with a linear sire model and standard REMLBLUP procedures, ignoring the binary nature of the trait. Variance components were estimated with REML using the program VCE4 (Neumaier and Groeneveld, 1998), and the PEST program (Groeneveld and Kovac,
1990) was used for prediction of sire transmitting abilities. Variance component estimates and predicted transmitting abilities (PTA) for sires were obtained using the following linear model:

$$
\mathrm{Y}_{\mathrm{ijklm}}=\mathrm{A}_{\mathrm{i}}+\mathrm{MY}_{\mathrm{j}}+\mathrm{h}_{\mathrm{k}}+\mathrm{s}_{\mathrm{l}}+\mathrm{e}_{\mathrm{ijkl} \mathrm{m}}
$$

where $\mathrm{Y}_{\mathrm{ijklm}}$ is the observation for $\mathrm{CM}(0=$ no mastitis, 1 = mastitis) of daughter $m$ of sire $l$, and the other effects are as for the threshold model, with age $\left(\mathrm{A}_{\mathrm{i}}\right)$ and month $\times$ year $\left(\mathrm{MY}_{\mathrm{j}}\right)$ of first calving treated as fixed effects, and herd $\times$ period $\left(\mathrm{h}_{\mathrm{k}}\right)$ and transmitting abilities of sires $\left(\mathrm{s}_{1}\right)$ as random effects. The residual was assumed to be normally distributed with mean 0 and variance $\sigma^{2}$. The evolution of PTAs of sires by calving-year of daughters was used to describe genetic changes in the cow population.

\section{RESULTS AND DISCUSSION}

Means, standard deviations, and quantiles of the posterior distributions of the variance components and of heritability of liability to $\mathrm{CM}$ are given in Table 2 . Herd variation and sire variation accounted for about $12.5 \%$ and $1.6 \%$ of the variation in the liability scale, respectively. The posterior distributions of the parameters were sharp (the posterior coefficient of variation was roughly $4 \%$ ) and symmetric, as illustrated in Figure 2 , showing the posterior distribution of heritability of liability to CM. The posterior mean (SD) of heritability of liability to CM was 0.066 (0.003), and the $95 \%$ central credibility interval was 0.06 to 0.07 , indicating precise inference. The point estimate is in agreement with published results from analyses of Nordic mastitis data using threshold models, with heritability estimates ranging from 0.06 to 0.12 (Simianer et al., 1991; Lund et al., 1999; Heringstad et al., 2001b).

Figure 3 shows averages of sire posterior means in the liability scale by birth-year of sires. The plot is approximately flat, suggesting little or no genetic change for CM in progeny tested bulls born from 1973 to 1993 . The corresponding posterior distribution of annual genetic change of liability to CM for these bulls is

Table 2. Means, standard deviations (SD), and quantiles of the posterior distributions of sire variance $\left(\sigma_{\mathrm{s}}^{2}\right)$, herd variance $\left(\sigma_{\mathrm{h}}{ }^{2}\right)$, and of heritability ${ }^{1}\left(\mathrm{~h}^{2}\right)$ of liability to clinical mastitis, estimated with the threshold

\begin{tabular}{|c|c|c|c|c|c|c|}
\hline \multirow[b]{2}{*}{ Parameter } & \multicolumn{2}{|c|}{ Posterior } & \multicolumn{3}{|c|}{ Quantiles } & \multirow{2}{*}{$\begin{array}{l}\mathrm{SE} \text { of } \\
\text { mean }\end{array}$} \\
\hline & Mean & SD & $2.5 \%$ & $50 \%$ & $97.5 \%$ & \\
\hline$\sigma_{\mathrm{s}}^{2}$ & 0.019 & 0.0008 & 0.018 & 0.019 & 0.021 & 0.00001 \\
\hline$\sigma_{\mathrm{h}}^{2}$ & 0.146 & 0.0016 & 0.143 & 0.146 & 0.150 & 0.00003 \\
\hline$h^{2}$ & 0.066 & 0.0028 & 0.061 & 0.066 & 0.072 & 0.00003 \\
\hline
\end{tabular}
model. Monte Carlo standard error (SE) of the posterior mean is also included. 


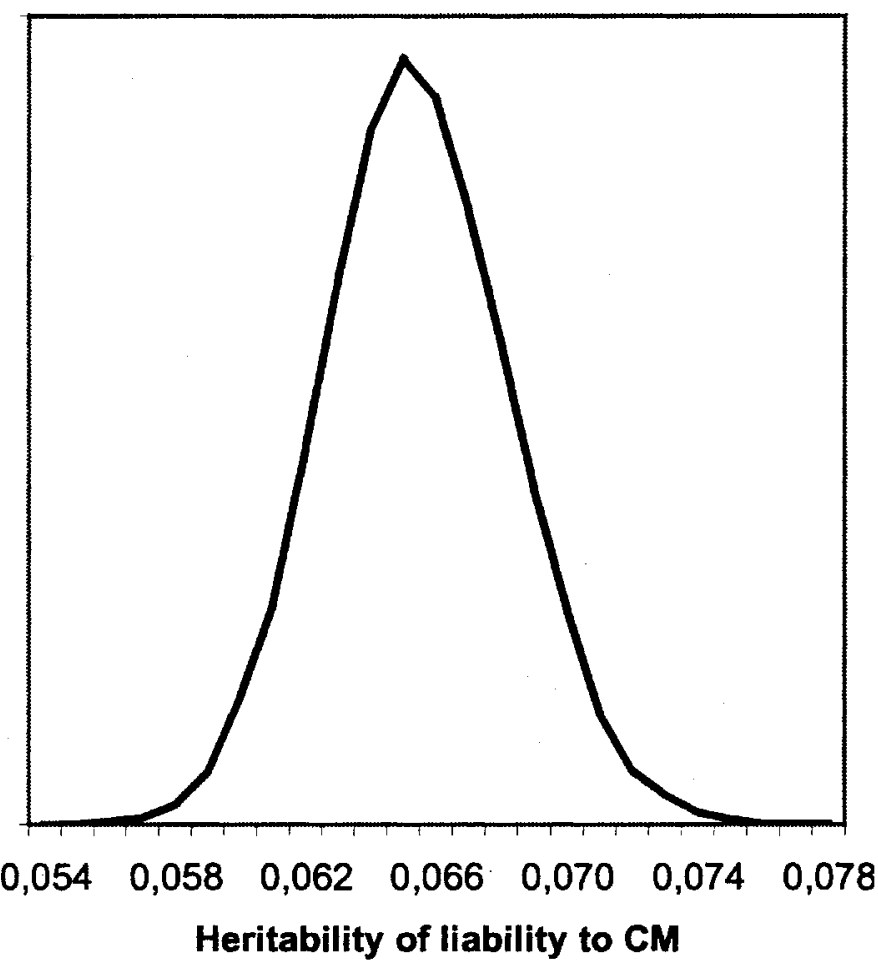

Figure 2. Posterior distribution of heritability $\left(\mathrm{h}^{2}=4 \sigma_{\mathrm{s}}^{2}\right) /\left(\sigma_{\mathrm{s}}^{2}+\right.$ $\left.\sigma^{2}{ }_{h}+1\right)$ ) of liability to clinical mastitis (CM) in the threshold model.

given in Figure 4. The sharp and symmetric distribution indicates that genetic change in the liability scale was inferred precisely in this population. The value 0 appears with reasonably high density, and the posterior

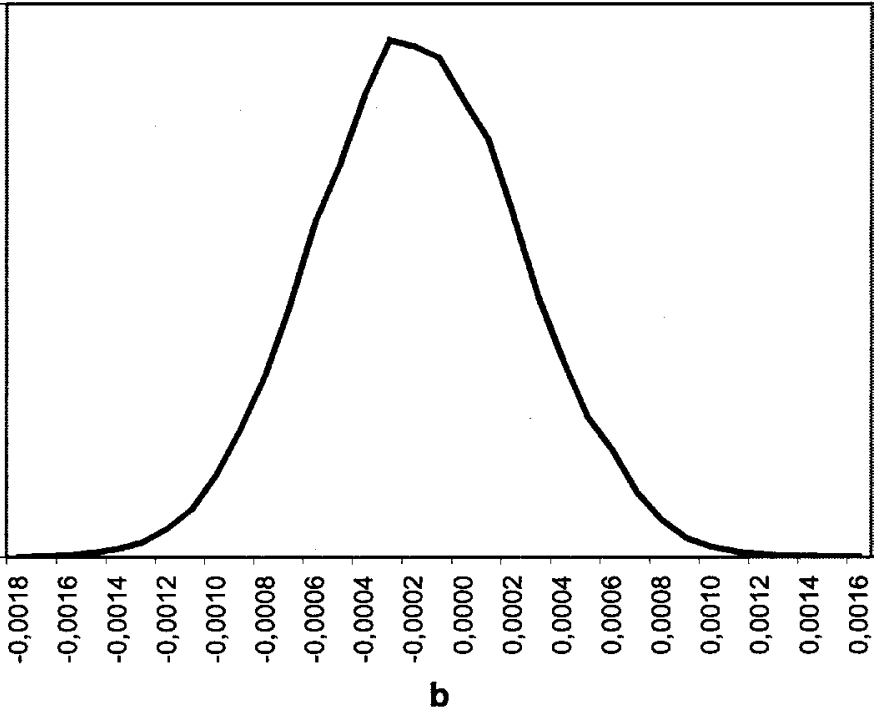

Figure 4. Posterior distribution of annual genetic change in liability to clinical mastitis for progeny tested bulls born from 1973 to 1993, computed as the regression (b) of sire effects on their birth-year.

mean (SD) of genetic change was -0.00018 (0.0004). This is consistent with the results in Figure 3.

The plots of average sire posterior means (probability scale, threshold model) and of BLUP-PTAs (linear model) by birth-year of daughters are given in Figure 5 . This plot describes, in some sense, the genetic change taking place in successive cohorts of cows. Figure 5 shows approximately no genetic change in CM for cows born from 1976 to 1990 and genetic improvement for

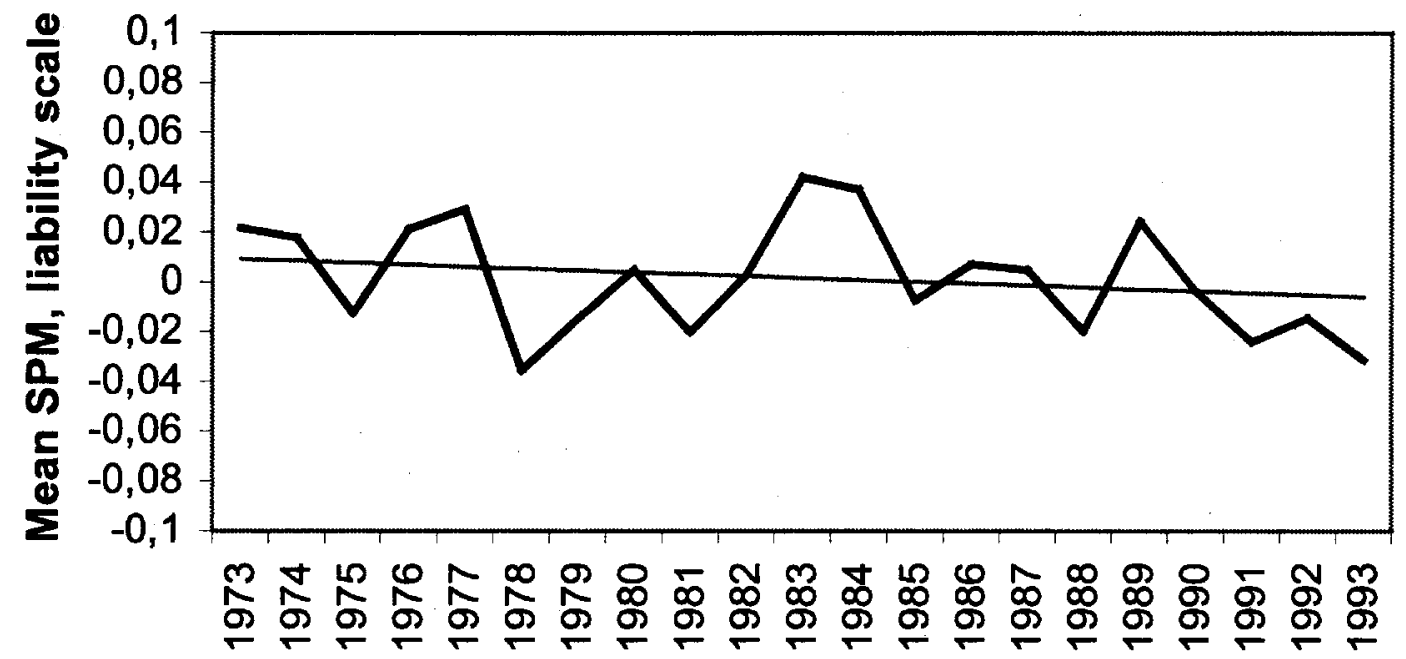

Birth year sires

Figure 3. Genetic change in clinical mastitis for progeny tested bulls, given as average sire posterior mean (SPM) of liability to clinical mastitis by birth-year of sires, and the corresponding linear regression. 


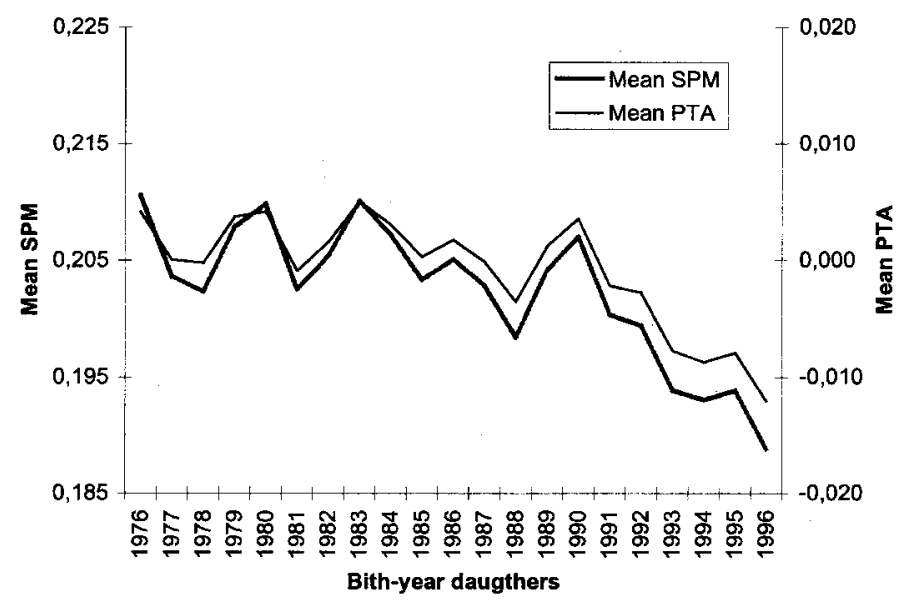

Figure 5. Plot of average sire posterior mean (SPM) in the probability scale (threshold model) and mean predicted transmitting ability (BLUP-PTA) of sires by birth-year of daughters.

cows born after 1990. For example, the average transmitting ability for CM of sires of cows born in 1996 was roughly $1.5 \%$ lower than for sires of cows born in 1990. The linear regressions of sire posterior means (probability scale) on birth-year of daughters (Table 3) showed a decrease of $0.02 \%$ CM per year (1976 to 1990) and $0.27 \%$ CM per year (1990 to 1996). There was an average decrease of $0.08 \% \mathrm{CM}$ per year for the whole period from 1976 to 1996.

Lack of genetic change for cows born before 1990 (Figure 5) suggests that the relative weight placed on mastitis in that period may have been large enough to counteract the unfavorable expected correlated response due to selection for increased milk production. The favorable genetic change in clinical mastitis for cows born after 1990 (Figure 5) is, arguably, a result of the increased weight placed on clinical mastitis, relative to milk production, in the total merit index in recent years (Heringstad et al., 2001a). In the NRF population,

Table 3. Linear regressions of sire posterior mean (SPM) in the probability scale from the threshold model, and of predicted transmitting ability (BLUP-PTA) from the linear model, on birth-year of sires and birth-year of daughters.

\begin{tabular}{llll}
\hline $\begin{array}{l}\text { Dependent } \\
\text { variable }\end{array}$ & Independent variable & Period & $\begin{array}{l}\text { Regression } \\
\text { coefficient } \\
(\times 100)\end{array}$ \\
\hline SPM & Birth-year, sires & $1973-1993$ & -0.02 \\
& & $1983-1993$ & -0.16 \\
SPM & Birth-year, daughters & $1976-1996$ & -0.08 \\
& & $1976-1990$ & -0.02 \\
PTA & Birth-year, daughters & $1990-1996$ & -0.27 \\
& & $1976-1996$ & -0.06 \\
& & $1990-1990$ & -0.01 \\
& & & -0.23 \\
\hline
\end{tabular}

about $40 \%$ of the sires of cows are young-sires, while $60 \%$ are elite-sires selected based on their total merit index. Increased weight on mastitis in the total merit index implies that the elite-sires that have been selected in recent years, on average, are genetically less susceptible to the disease. In short, genetic improvement of mastitis resistance via selection is feasible, at least in the NRF population. This is in agreement with Heringstad et al. (2001a) who, based on selection differentials of bull-sires, found that genetic gain for CM can be expected with NRF's current breeding program.

In the Finnish Ayrshire population, mastitis has been included in the total merit index for bulls since 1986 . Juga et al. (1999) reported a favorable genetic trend for Finnish Ayrshire bulls born from 1983 to 1993, amounting to a genetic decrease of $0.15 \% \mathrm{CM}$ per year. For the NRF bulls born in the same period, the regression analyses of sire posterior means on birth year of sires showed a genetic decrease of $0.16 \% \mathrm{CM}$ per year (Table 3), which is in close agreement with the Finnish results.

The estimated variance components from the linear sire model were $0.00095,0.00754$, and 0.12351 for sires, herds, and residuals, respectively. The corresponding heritability was 0.03 , which is in accordance with a review of heritability estimates of $\mathrm{CM}$ from linear models (Heringstad et al., 2000). The trend of mean BLUPPTA for CM from the linear sire model is given in Figure 5 , together with results from the threshold model. The regression of PTA of sires on birth-year of daughters showed a decrease of $0.06 \% \mathrm{CM}$ per year in the period from 1976 to 1996 and a decrease of $0.23 \% \mathrm{CM}$ per year from 1990 to 1996 (Table 3), which is slightly smaller in absolute value than the change estimated with the threshold model. Hence, and to the extent that the threshold model holds true, the magnitude of genetic change might be slightly understated by the linear model in this dataset. This is probably due to the fact that the threshold model captures more genetic variance, as revealed by the larger heritability. The rank correlation between sire evaluations based on the threshold model and on the linear model was larger than 0.99, which is in agreement with other studies (Meijering, 1985; Weller et al., 1988). This is not surprising in view of the large progeny groups (664 daughters per sire, Table 1), making averages of 0 to 1 records close to normally distributed. In brief, our results suggest that differences in inferences between a threshold model and a linear model can be more marked for estimating genetic variance and genetic change than for ranking sires, at least for large progeny groups.

These studies of genetic change should be viewed with caution. Our analysis is a single-trait one, using $\mathrm{CM}$ information only. Since selection in the NRF popu- 
lation is based on a multi-trait objective, the history of the selection process is not contained entirely in the $\mathrm{CM}$ information. Hence, selection is not of the ignorable type, as described by Sorensen et al. (2001). An appropriate analysis of trends ought to be based on a multivariate model including CM, protein yield, fertility, and all other traits used for selection, but this is not computationally feasible at present. However, Heringstad et al. (2001a) showed in a linear model analyses that trends in sire EBVs for CM in the NRF population were similar in a univariate analysis of $\mathrm{CM}$ and in a bivariate analysis of $\mathrm{CM}$ and protein yield. This indicates that a single-trait analysis for CM may be sufficient for estimation of genetic change for the disease in this population.

Only records for first-parity cows were used in this study, as this is what is currently used in genetic evaluation for CM in Norway. The analysis can be extended to include mastitis information from second and later lactations. In general, the incidence of CM is higher in older cows, and adding these data would increase sire reliabilities and alleviate the extreme category problem.

In conclusion, genetic improvement of mastitis resistance is seemingly being achieved in NRF. Our results, together with those of Andersen-Ranberg et al. (2001) and Heringstad et al. (2001a), showing genetic improvement for heifer fertility and protein yield, respectively, demonstrate that with a broad breeding objective it is possible to obtain simultaneous genetic progress for milk production, health, and fertility, despite the unfavorable genetic correlations between traits and the low heritability of some of the traits.

\section{ACKNOWLEDGMENTS}

Access to the data was given by the Norwegian Dairy Herd Recording System and the Norwegian Cattle Health Service in agreement number 011.2000 by 12.10.2000. GENO Breeding and AI Association is acknowledged for providing pedigree information on sires. This work is part of the "Healthy Cow" project financed by the Research Council of Norway. Support has also been received from the Babcock Institute for International Dairy Research and Development, University of Wisconsin, Madison, and by grants NDF DEB-0089742 and NRICGP/USDA 99-35205-8162.

\section{REFERENCES}

Albert, J., and S. Chib. 1993. Bayesian analysis of binary and polychotomous response data. J. Am. Stat. Assn. 88:669-679.
Andersen-Ranberg, I. M., G. Klemetsdal, B. Heringstad, and M. Svendsen. 2001. Heifer fertility in Norwegian Cattle; genetic parameters and genetic trend. Page 45 in Book of Abstr. 52nd Ann. Mtg. of the EAAP, Budapest, Hungary, Wageningen Pers, Wageningen, The Netherlands.

Gianola, D. 1982. Theory and analysis of threshold characters. J. Anim. Sci. 54:1079-1096.

Gianola, D., and J. L. Foulley. 1983. Sire evaluation for ordered categorical data with a threshold model. Genet. Sel. Evol. 15:201-223.

Groeneveld, E., and M. Kovac. 1990. A generalized computing procedure for setting up and solving mixed linear models. J. Dairy Sci. 73:513-531.

Heringstad, B., G. Klemetsdal, and J. Ruane. 1999. Clinical mastitis in Norwegian Cattle: Frequency, variance components and genetic correlation with protein yield. J. Dairy Sci. 82:1325-1330.

Heringstad, B., G. Klemetsdal, and J. Ruane. 2000. Selection for mastitis resistance in dairy cattle-A review with focus on the situation in the Nordic countries. Livest. Prod. Sci. 64:95-106.

Heringstad, B., G. Klemetsdal, and J. Ruane. 2001a. Responses to selection against clinical mastitis in the Norwegian Cattle population. Acta Agric. Scand., Sect A. Anim. Sci. 51:155-160.

Heringstad, B., R. Rekaya, D. Gianola, G. Klemetsdal, and K. A. Weigel. 2001b. Bayesian analysis of liability to clinical mastitis in Norwegian Cattle with a threshold model; effects of data sampling method and model specification. J. Dairy Sci. 84:2337-2346.

Juga, J., E. A. Mantysaari, and J. Pösö. 1999. Economic responses to total merit selection in Finnish Ayrshire breeding. Pages 7988 in Proc. Int. Workshop on EU Concerted Action on Genetic Improvement of Functional Traits in Cattle (GIFT); Breeding Goals and Selection Schemes. Interbull Bulletin no. 23, Int. Bull Eval. Serv., Uppsala, Sweden.

Lund, M. S., J. Jensen, and P. H. Petersen. 1999. Estimation of genetic and phenotypic parameters for clinical mastitis, somatic cell production deviance, and protein yield in dairy cattle using Gibbs sampling. J. Dairy Sci. 82:1045-1051.

Meijering, A. 1985. Sire evaluation for calving traits by Best Linear Unbiased Prediction and nonlinear methodology. Z. Tierz. 102:95-105.

Neumaier, A., and E. Groeneveld. 1998. Restricted maximum likelihood of covariances in sparse linear models. Genet. Sel. Evol. 30:3-26.

Raftery, A. L., and S. Lewis. 1992. How many iterations in the Gibbs sampler? Pages 763-774 in Bayesian Statistics 4. J. M. Bernando, J. O. Berger, A. P. Dawid, and A. F. M. Smith, ed. Oxford University Press, Oxford, UK.

Rekaya, R., K. A. Weigel, D. Gianola, B. Heringstad, and G. Klemetsdal. 2000. Methods for attenuating bias of variance component estimates in threshold models when herds are small. J. Dairy Sci. 83:(Suppl. 1):56-57.

Simianer, H., H. Solbu, and L. R. Schaeffer. 1991. Estimated genetic correlations between disease and yield traits in dairy cattle. J. Dairy Sci. 74:4358-4365.

Sorensen, D. A., S. Andersen, D. Gianola, and I. Korsgaard. 1995. Bayesian inference in threshold models using Gibbs sampling. Genet. Sel. Evol. 27:229-249.

Sorensen, D., R. Fernando, and D. Gianola. 2001. Inferring the trajectory of genetic variance in the course of artificial selection. Genet. Res. 77:83-94.

Weller, J. I., I. Misztal, and D. Gianola. 1988. Genetic analysis of dystrocia and calf mortality in Israelian Holstein by threshold and linear models. J. Dairy Sci. 71:2491-2501.

Wright, S. 1934. An analysis of variability in number of digits in an inbred strain of Guinea pigs. Genetics 19:506-536. 